\title{
PENSAR EL ESPACIO PÚBLICO ENTRE EL ESTADO Y LAS RELIGIONES: UNA PROPUESTA A PARTIR DE LA INTERACCIÓN EN LUGARES SOCIALMENTE SIGNIFICATIVOS
}

\section{- MARÍA PILAR GARCÍA BOSSIO ${ }^{1}$}

${ }_{1}^{1}$ Profesora en Sociología (UNLP). Becaria doctoral del CONICET con lugar de trabajo en el Instituto de Investigaciones de la Facultad de Ciencias Sociales (UCA). Doctoranda en Ciencias Sociales por la Universidad de Buenos Aires. Docente en la Universidad Torcuato Di Tella. Email para contacto: mapilargarciabossio@gmail.com.

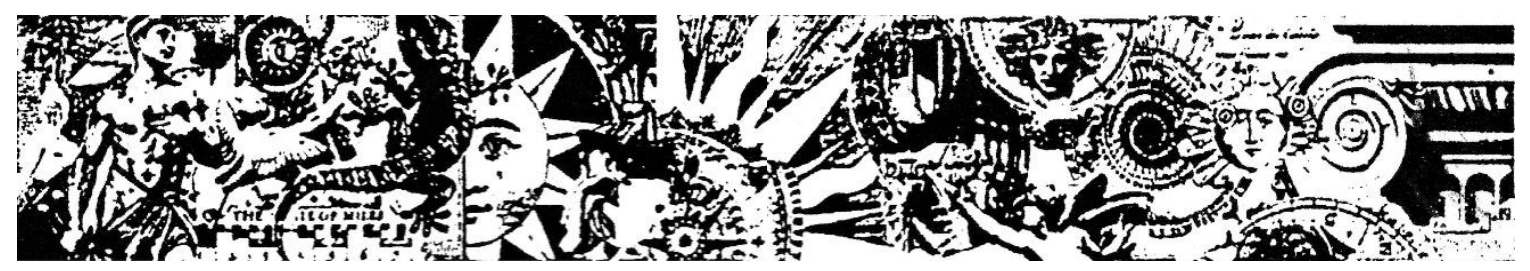

Resumen: En este trabajo nos proponemos indagar en las formas en que las religiones interactúan con el Estado en el espacio pública, como un tipo de regulación molecular, que va más allá de la implementación de normas formales, y donde la escala de jerarquización religiosa existente en Argentina se vuelve más porasa. Рara ello analizaremos las actividades realizadas en distintos lugares, seculares y religiosos, por tres organismos estatales de la esfera subnacional argentina - uno de la ciudad de Buenos Aires, uno provincial bonaerense y uno municipal bonaerense - a a fin de proponer una tipología de sus formas de actuación. Esperamos desde allí poder indagar en las consecuencias de estas interacciones coma una farma de regulación que no sóla se produce desde el Estada hacia las religiones, sino que también nos permite pensar cómo las religiones intervienen en la estatal a partir de su visibilización e intervención en el espacio público.

Palabras claves: religión-Estado-Buenos Aires-Espacio público 
THINKING ABDUT THE PUBLIC SPACE BETWEEN THE STATE AND RELIGIINS: A PRDPOSAL BASED QN INTERACTIIN IN SOCIALLY SIGNIFICANT PLACES

ABSTRACT: IN THIS ARTILLE, WE PROPOSE TO INVESTIGATE THE WAYS IN WHICH RELIGIINS INTERACT WITH THE STATE IN THE PUBLIC SPACE, AS A TYPE OF MDLECULAR REGLLATION, WHICH GDES BEYGND THE IMPLEMENTATION OF FORMAL NDRMS, AND WHERE HIERARCHICAL ORGANIZATION OF RELIGIONS IN ARGENTINA BECDMES MORE PORDUS. TO DO THIS. WE WILL ANALYSE THE ACTIVITIES CARRIED QUT IN DIFFERENT PLACES, SECULAR AND RELIGIOUS, BY THREE STATE AGENCIES IN THE ARGENTINE SUB-NATIONAL SPHERE - QNE IN THE CITY OF BUENDS AIRES, QNE IN THE PRDVINCE OF BUENDS AIRES AND ONE IN THE CITY DF LA PLATA - IN QRDER TQ PROPOSE A TYPDLIGY OF PLACES AND ACTING FORMS. WE HOPE FROM THERE TO BE ABLE TQ INVESTIGATE THE CONSEQUENCES OF THESE INTERACTIONS AS A FDRM OF REGULATION THAT NDT ONLY DCCURS FRDM THE STATE TO RELIGIONS, BUT ALSD ALLOWS US TQ THINK ABDUT HOW RELIGIONS INVDLVED IN THE STATE THROUGH THEIR VISIBILITY AND INTERVENTIUN IN THE PUBLIC SPACE.

KEYWDRDS: RELIGIIN, STATE, BUENDS AIRES, PUBLIC SPACE.

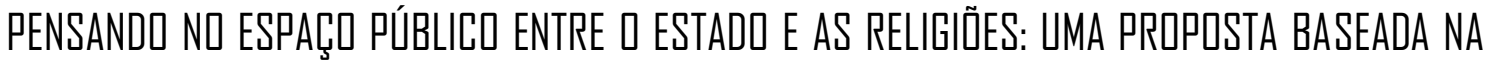 INTERAÇÃ̃ EM LUGARES SOCIALMENTE SIGNIFICATIVUS}

RESUMEN: NESTE TRABALHO, PROPOMUS INVESTIGAR AS MANEIRAS PELAS QUAIS AS RELIGIÕES INTERAGEM CDM Q ESTADO ND

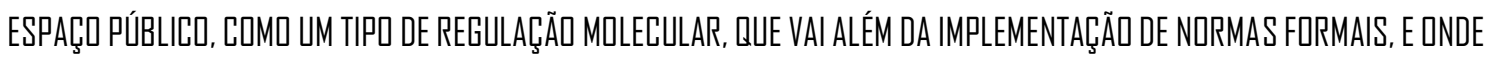

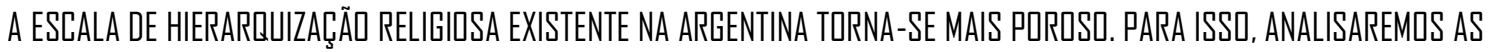
ATIVIDADES REALIZADAS EM DIFERENTES LDCAIS, SECULARES E RELIGIOSDS, POR TRÊS ÓRGÃOS ESTADUAIS NA ESFERA SUBNACIONAL ARGENTINA - UM NA CIDADE DE BUIENDS AIRES, UM NA PRDVÍNCIA DE BUENDS AIRES E QUTRD NA IDADE DE LA PLATA - PARA PROPOR UMA TIPOLIGGIA DE SUAS FORMAS DE AÇÃU. ESPERAMUS, A PARTIIR DE AÍ PODER INVESTIGAR AS

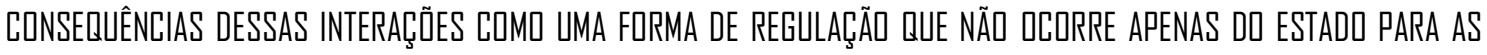
RELIIIÕES, MAS TAMBÉM NDS PERMITE PENSAR EM CDMD AS RELIGIÕES INTERVÊM ND ESTADD ATRAVÉS DE SUA VISIBILIDADE E INTERVENÇ̃̃̃ ND ESPAÇD PÍBLICD.

PALABRAS CLAVE: RELIIIÃ̃, ESTADD, BUENDS AIRES, ESPAÇD PÚBLICD.

\section{Introducción}

Las religiones, en tanto actividades sociales, forman parte de la construcción del espacio público en una sociedad. Las formas en que están presentes en ese espacio dan cuenta de sus distintos modos de legitimación social y de vinculación con los dispositivos estatales (GIUMBELLI, 2008) que atraviesan los territorios nacionales, con sus configuraciones subnacionales y locales.

En este trabajo nos proponemos indagar en las formas en que las religiones interactúan con el Estado en el espacio público, como un tipo de regulación molecular (GIUMBELLI, 2013), que va más allá de la implementación de normas formales, y donde la escala de jerarquización religiosa existente en Argentina (FRIGERIO Y WYNARCZYK, 2008) se vuelve más porosa. Nuestro punto de vista será a través del ESPAÇO E CULTURA, UERJ, RJ, JUN./JUL DE 2020, N. 47, P. 55-80. http://www.e-publicacoes.uerj.br/index.php/espacoecultura/ 
Estado, pero no concebido como un todo omnipotente y monolítico, sino que buscaremos dar cuenta de su funcionamiento a nivel de las burocracias locales, haciendo un análisis de sus prácticas cotidianas y de su construcción discursiva en la cultura pública (GUPTA, 2015, p. 73) con relación a lo religioso.

Tomaremos tres organismos estatales de nivel subnacional cuya función principal es la de relacionarse con las religiones en su territorio: la Dirección General de Cultos de la Ciudad de Buenos Aires; la Dirección Provincial de Cultos de la provincia de Buenos Aires y la Dirección de Entidades y Culto de la ciudad de La Plata ${ }^{2}$. Estas oficinas, de creaciones relativamente recientes, son una instancia del amplio entramado de las relaciones que las diversas religiones establecen con mayor o menor eficacia con el Estado (CELA HEFFEL, 2015). Si bien no son el único (y muchas veces tampoco el principal) canal de diálogo y disputa entre el Estado y las religiones, sí nos interesa destacar que su función principal es establecer estos vínculos, buscando encauzarlos a través de un sistema de "ventanilla única" de acceso al entramado estatal. En este sentido, las tres juegan un rol importante en la habilitación (o no) de la presencia institucional de las religiones que comprenden sus territorios en el espacio público. Si bien las tres pertenecen a distintos niveles de gobierno - ciudad autónoma ${ }^{3}$, provincia y municipio bonaerense - la comparación de su actuación respecto a las religiones nos permitirá distinguir ciertas regularidades que nos habilitarán a presentar una tipología de los lugares socialmente significativos (FRIGERIO, 2017) que se construyen entre estos actores y las religiones que habitan sus territorios, configurando la forma en que percibimos (al menos una parte) del espacio público.

El material que hemos utilizado para construir la tipología proviene de una investigación de más largo aliento (en el marco de mi formación doctoral), y se conforma a partir del relevamiento de normativa estatal, publicaciones periódicas estatales, religiosas y de medios de difusión masiva; y el abordaje etnográfico de instancias de interacción entre los agentes de las direcciones y miembros de distintas religiones. El

\footnotetext{
2 A lo largo del período del trabajo de campo las tres oficinas han sufrido cambios en sus denominaciones y el sitio que ocupan en el organigrama estatal. Nos referiremos a ellas con el nombre y jerarquía en la que permanecieron la mayor parte del trabajo de campo, indicando cuando sea necesario si sufrieron modificaciones.

${ }^{3}$ La ciudad de Buenos Aires, es la capital del país y es autónoma, por lo que cuenta con su propia Constitución y organización, independiente de cualquier poder provincial. En este sentido, no puede ser igualada a otros municipios del país, porque legalmente tiene otro estatuto. Esto, sumado a que concentra una fuerte actividad productiva, le permite disponer de un presupuesto más rico que el de cualquiera de los otros municipios. 
trabajo de campo se ha desarrollado entre 2015 y 2019 y ha sido complementado con entrevistas semiestructuradas a los directores de la Dirección Provincial de Cultos y la Dirección de Entidades y Culto de La Plata, como conversaciones informales con agentes de las tres direcciones, de otras dependencias estatales y de diversas religiones.

Esperamos a partir de esta tipología poder indagar cómo estas interacciones forman parte de una forma de regulación que no sólo se produce desde el Estado hacia las religiones, sino que también nos permite pensar cómo las religiones intervienen en lo estatal, configurándose en esta relación de doble vía una forma de experienciar el espacio público. Introduciremos algunas definiciones teóricas, y contextuales, para luego presentar la tipología y, finalmente, observar su aplicación a los casos estudiados.

\section{Espacio, lugares y religión}

Existe una profusa bibliografía sobre las vinculaciones entre religión y espacio, desde distintas disciplinas de las ciencias sociales. Cada definición configura una manera de jerarquizar los conceptos y delimita el marco con el que vamos a analizar la información que hemos recabado en nuestro trabajo de campo.

Funes (2019) propone una tipificación de los trabajos que estudian la relación entre religión y espacio en América Latina en tres grandes ejes: aquellos que buscan identificar marcas que las prácticas e instituciones religiosas depositan en el espacio, en general en ámbitos urbanos de distintas densidades; aquellos que analizan la vida religiosa y la configuración del espacio en perspectiva histórica (la autora incorpora aquí análisis de largo plazo sobre las transformaciones en las formas en que definen el territorio grupos religiosos y Estado); y aquellos que comprenden a la religiosidad y al espacio como dimensiones mutuamente influyentes, en la construcción de identidades colectivas y modos de vida en un espacio particular.

Consideramos que nuestro trabajo puede ubicarse en la bisagra de los dos primeros ejes, pues buscamos problematizar "la influencia de la religión en los usos del espacio urbano y muestran que la distribución y la (in)visibilidad de la vida religiosa en el espacio es, en parte, una expresión de los modos de regulación de lo religioso por el Estado y la sociedad civil” (FUNES, 2019, p. 218); a la vez que intentamos dar cuenta del proceso histórico que configura una territorialidad estatal específica, en un contex to de cambio de las políticas de la identidad (SEGATO, 2007, 2008). En este sentido, si bien no profundizaremos en la forma de categorización del territorio propuesta por 
Segato, sí estamos de acuerdo con su indicación del debilitamiento del Estado moderno hace surgir con fuerza en el espacio público las identidades religiosas (entre otras), aunque consideramos que parte de esta visibilización viene de la mano de obtener reconocimiento por parte de un Estado que, aunque debilitado, sigue siendo fuente de regulación y legitimidad.

Por su parte, Flores (2015, 2018) nos permite pensar en el espacio en su materialidad, pero también en su inmaterialidad, en tanto son los actores los que con su accionar y percibir van configurando qué se comprende como espacio y cómo será vivenciado. En este punto Flores discute la trampa de pensar la dicotomía entre espacio sagrado y espacio profano, para proponer (a partir de la experiencia del peregrinar) que "no hay una sacralidad propia de ciertos espacios y una profanidad propia de otros" (FLORES, 201, p. 130), sino que es la práctica la que los configura como tales por el tiempo en que esta perdure. Esto no quiere decir, sin embargo, que no existan relaciones asimétricas de poder en la configuración del espacio sagrado (pensemos aquí en el rol de los especialistas religiosos, importante además en nuestro caso porque son los que dialogan con el Estado), pero abre la puerta a pensar que las prácticas de sacralización (al decir de MARTÍN, 2007) puedan romper con una tipificación que solo mire el espacio como una materialidad con un sentido fijado de una vez y para siempre.

Es por eso que Flores (2018) propone hablar de lugares sagrados, entendiéndolos como construcción social, donde una fracción del espacio se destaca por la manifestación de atributos cualitativos de hierofanía, a partir de prácticas de sacralización que se ponen en juego allí. Tomaremos de aquí la importancia de ver los lugares, para construir nuestra tipología a partir de la articulación en lugares socialmente significativos, es decir, de lugares que son (o se convierten) importantes para emplazar actividades religiosas o seculares. Si bien comprendemos que para la Geografía todo lugar es un ámbito del espacio anclado en una significatividad social (con sus relaciones y procesos identitarios), mantendremos la distinción de socialmente significativos propuesta por Frigerio, porque consideramos que deja de manifiesto que nos referimos a lugares que son inteligibles como importantes para un grupo grande de la sociedad, y es por eso que entra en disputa su uso por agentes estatales y religiosos. Construimos esta categoría a partir del trabajo de Frigerio (2017) en el cual analiza el impacto social del surgimiento de iglesias evangélicas pentecostales en teatros y cines céntricos de ciudad de Buenos Aires, y cómo esto tensionó la legitimidad de estas prácticas religiosas allí donde se había hecho culto a una secularidad que era símbolo de 
un imaginario de Argentina como país blanco, europeo, moderno y católico (entendiendo esto último más como una cultura católica secularizada que como una práctica religiosa concreta).

De esta manera nuestra tipología buscará mostrar cómo la intervención de las religiones y el Estado en lugares socialmente significativos (para ellos, y para la sociedad en general) da forma a una manera de interactuar en el espacio público, y cómo prácticas de sacralización y de legitimación cristalizan en la configuración de un territorio marcado por la presencia de la acción estatal.

\section{La regulación de la religión en Argentina}

Antes de indagar sobre la configuración del espacio público en niveles subnacionales y locales, consideramos pertinente remitirnos a algunas características generales de la forma en que el Estado argentino ha configurado su territorio, particularmente en lo concerniente a la interacción histórica con las diversas religiones que lo habitan.

Debemos considerar que en Argentina, como en gran parte de América Latina, prevalece una identificación social con el catolicismo, pero al mismo tiempo existe una rica diversidad religiosa, que se ha visibilizado progresivamente durante los últimos cuarenta años. Metodológicamente nos encontramos con una seria dificultad para traducir esta experiencia en datos cuantitativos, pues en el país el censo no pregunta por pertenencia religiosa desde 1960 (y cuando se hizo fue de manera intermitente). De esta forma podemos tener una noción numérica general a partir de organismos internacionales y del esfuerzo reciente de instituciones académicas. En este sentido, el programa Sociedad, Cultura y Religión del CEIL-CONICET cuenta con dos encuestas (realizadas a mayores de 18 años en localidades de al menos 5000 habitantes), con una distancia de 11 años (2008 y 2019), que nos permiten acceder a datos generales y poder realizar comparaciones. Para 2019, el 62,9\% de la población se identificaba como católica; 18,9\% sin religión; 15,3\% evangélica (13\% pentecostales y 2,3\% otros evangélicos); 1,4\% como mormones o testigos de Jehová y 1,2\% como practicante de otras religiones (con un 0,3\% sin respuesta) (MALLIMACI y OTROS, 2019). Estos datos nos servirán para dimensionar la capacidad de distintas comunidades de dialogar con el Estado.

En términos de la organización estatal, a nivel legal la Iglesia Católica ha gozado históricamente de un estatuto preferencial frente a las otras religiones en el ESPAÇO E CULTURA, UERJ, RJ, JUN./JUL DE 2020, N. 47, P. 55-80. http://www.e-publicacoes.uerj.br/index.php/espacoecultura/ 
territorio nacional, tanto por el sostenimiento al que se compromete la Constitución Nacional en su artículo 2 (y con el cual la provincia de Buenos Aires coopera según el artículo 9 de su Constitución provincial) ${ }^{4}$, como - y, sobre todo - por su carácter de persona jurídica pública. Esto está establecido por el Código Civil y Comercial (MALLIMACI, 2015), el cual incluye entre las personas jurídicas públicas a la Iglesia Católica, lo que le da el mismo estatuto legal que al Estado; mientras clasifica a las demás religiones como persona jurídica privada, igualándolas a cualquier otra organización de la sociedad civil. Estas dos condiciones, la del sostenimiento del culto católico desde lo constitucional, y su carácter de persona jurídica pública, establecen una divisoria que se sostiene luego en el entramado institucional estatal. De esta manera, la Secretaría de Culto de la Nación establece una distinción entre culto católico y culto no católico que obliga a estas religiones a inscribirse en un Registro Nacional de Cultos, para ser reconocidas por el Estado (CATOGGIO, 2008), estableciéndose una situación donde se sostiene como derecho constitucional la libertad de culto, pero se exige una validación formal para su existencia en el territorio con aval gubernamental.

Esta configuración legal e institucional tiene su correlato en la forma en que el Estado argentino configuró su territorio, en un proceso donde Estado e Iglesia Católica se consolidaron institucionalmente al unísono (DI STEFANO, 2014). De esta manera el espacio público está signado por objetos fijos y móviles (FUNES, 2019) que remiten a la religión católica. Entre los primeros podemos enumerar símbolos religiosos en organismos estatales (imágenes de la Virgen María y crucifijos en oficinas públicas, juzgados, comisarías, etc.) y en lugares públicos (plazas, estaciones del transporte público, etc.); y entre los segundos, una serie de eventos masivos que cuentan con amplia legitimidad por parte del Estado y la sociedad, como peregrinaciones, misas por acontecimientos importantes (tanto religiosos como políticos), etc., que muchas veces cuentan con participación de agentes estatales y figuras sociales destacadas. Quizás el

\footnotetext{
4 "Artículo 2‥- El Gobierno federal sostiene el culto católico apostólico romano." (Constitución Nacional). Si bien hay otros artículos de la Constitución que ponen en relación Iglesia Católica y Estado, y religiones y Estado, este es el que más polémicas ha generado en torno a la idea de sostenimiento.

Al ser Argentina un país federal, cada provincia dicta su propia constitución, y establece sus propias normas, siempre respondiendo al gran marco de la Constitución Nacional. La provincia de Buenos Aires adhiere al principio nacional en su "Artículo 9.- El Gobierno de la Provincia coopera a sostener el culto Católico Apostólico Romano, con arreglo a las prescripciones de la Constitución Nacional." Así se ubica como una provincia de religión oficiosa, con preponderancia católica, según la clasificación propuesta por Esquivel (2009). Siguiendo esta clasificación, Ciudad de Buenos Aires, que desde 1994 tiene su propia constitución como ciudad autónoma, tiene un perfil pluralista respecto a lo religioso.
} 
ejemplo más claro de esta simbiosis entre Estado e Iglesia Católica se encuentra en el Tedeum, celebración inserta en nuestra tradición nacional, donde el Presidente de la Nación (o su correlato a niveles locales) asiste a una breve celebración ofrecida por la máxima autoridad eclesiástica (en este caso el Arzobispo de Buenos Aires). Este acto configura un pacto simbólico entre poder político y religioso en la constitución de la nación que se ha mantenido incluso cuando las relaciones entre el gobierno y la Iglesia Católica no fueran las mejores. Progresivamente, se han ido incorporando líderes de otras religiones, a veces como espectadores, a veces concelebrando, pero siempre emplazado en templos de la Iglesia Católica.

Si hemos visto hasta ahora cómo la regulación estatal moldea una serie de relaciones y de configuraciones espaciales, debemos incluir una fuerte regulación social, que desde el retorno de la democracia en Argentina en 1983 -año que significó una apertura respecto a la persecución estatal que el gobierno militar ejerció fuertemente sobre la diversidad religiosa ${ }^{5}$ - ha llevado a las religiones no católicas más estigmatizadas (como el evangelismo pentecostal y las religiones de matriz africana) a un largo proceso de disputa por su legitimidad en el espacio público. Siguiendo el recorte temporal propuesto por Frigerio y Wynarczyk (2008), podemos distinguir distintas instancias de ese proceso, desde la acusación de invasión extranjera de sectas (1985-1989), a la sospecha de realizar "lavados de cerebro" (1989-1991) y al pánico moral sobre las sectas (1992-1993), con un proyecto de ley de cultos altamente estigmatizante que no prosperó. Luego de una nueva instancia de conflicto (1994-1996) se consiguió un cierto aplacamiento del problema mediático (1997-2001) pero sólo gracias a la organización de estas religiones frente a un marco legal que no cambió significativamente durante los últimos cuarenta años (y cuya apertura dependió en gran medida del perfil personal de los agentes estatales dedicados a las tareas de vinculación religiosa). Estas distintas

\footnotetext{
${ }^{5}$ Todos los gobiernos de facto durante el siglo XX en Argentina supusieron una alianza estratégica con las jerarquías de la Iglesia Católica que ayudaron a consolidar el mito de la nación católica (MALLIMACI, 2015). En este sentido, la última dictadura cívico-militar no sólo reforzó esa tendencia, sino que también impulsó una vasta legislación que otorga beneficios a la Iglesia Católica y que regula estrictamente la presencia de diversidad religiosa (leyes aprobadas en un gobierno de facto que aún hoy se mantienen vigentes), a lo que sumó una abierta persecución a las religiones minoritarias. Dentro de esta regulación legal se encuentra la creación del ya mencionado Registro Nacional de Cultos. Si bien el Registro tiene como antecedente un "fichero de cultos" creado durante el primer gobierno de Juan Domingo Perón (1946-1952), fue la dictadura la que le dio un carácter policial, estableciendo requisitos muy estrictos para habilitar a las religiones no católicas a establecer relaciones con el Estado, siendo consideradas organizaciones peligrosas en caso contrario. Si bien estos requisitos se han ido flexibilizando a lo largo de los años el Registro aún se encuentra en funcionamiento, y los intentos de suprimirlo o modificarlo han fracasado. 
instancias sociales también dejaron huella en la configuración del espacio público y generaron un fuerte malestar cuando lugares socialmente significativos para el ideario de nación blanca, europea y católica (secularizada) se vieron transformados en lugares de culto religioso, particularmente evangélico, como hemos mencionado que destaca Frigerio (2017). De la misma manera, la estigmatización marcó a tal punto la configuración territorial que aún hoy muchos templos afrorreligiosos no tienen símbolos que permitan identificarlos desde la calle, permaneciendo ocultos al interior de fachadas de casas particulares.

En esta configuración del espacio público, en general, y de la construcción del territorio estatal, en particular, el nuevo milenio trajo aparejados una serie de cambios en el entramado estatal que, nuevamente, impactaron en las formas de vivenciar el espacio. Se empezaron a crear oficinas estatales en distintos niveles de gobierno, así como instancias institucionales dedicadas al trabajo con las religiones, lo que generó nuevas expectativas (CELA HEFFEL, 2015), y enfrentó tanto a las religiones como al Estado a nuevos desafíos, en un contexto donde la Iglesia Católica no pierde una cierta legitimidad fuertemente arraigada en su vinculación con el ideal de nación y con la presencia privilegiada en el espacio público (FRIGERIO, 2012).

Sin profundizar en las marcas fijas y móviles en el espacio público que hemos mencionado (y que han sido profusamente tratadas como señalan FLORES, 2018 y FUNES, 2019) nos concentraremos en las maneras en que tres de estas oficinas gestionan su intervención y la de las religiones en su territorio, en lugares seculares y religiosos para desde allí indagar en cómo se disputa la configuración simbólica del espacio público.

\section{Una tipología para pensar el espacio público}

Teniendo en cuenta las discusiones teóricas en las que nos enmarcamos, y la situación de las relaciones entre Estado y religiones a nivel general, profundizaremos en algunas experiencias donde ver la construcción de un espacio público en el que Estado, religiones y sociedad civil se encuentran en diálogo y tensión. Para ello, y a partir de la experiencia de campo, diseñamos una tipología de la interacción de agentes estatales y religiosos en lugares seculares y lugares religiosos, para pensar desde allí qué nos dice esto sobre el espacio público. 
Aquí concebimos tres tipos de lugares de interacción a los que consideramos públicos en un sentido amplio, en tanto son de acceso a todo público (más allá de la condición legal de la propiedad como privada o pública), esto incluye locales, calles, instituciones, templos, plazas (ALGRANTI y OTROS, 2013). Distinguimos entre lugares seculares (FRIGERIO, 2017, p. 275), es decir, aquellos que no son considerados lugares sagrados o religiosos por los actores; y lugares religiosos. Entre los primeros distinguimos lugares al aire libre - plazas, parques, áreas recreativas, como así también rutas, calles - a los que cualquier transeúnte tiene acceso, y por tanto incluso quien no esté interesado en el evento puede verlo o acceder a él; y lugares estatales - oficinas públicas, y edificios públicos en general -, los cuales son vistos como lugares socialmente significativos en la materialización del Estado en el espacio público. Estos son reconocidos como lugares seculares, a la vez que son arena de disputa en la que las religiones buscan intervenir, dejando marcas fijas o al menos presencias móviles. Finalmente, definimos los lugares religiosos - templos, salas de reunión, oficinas, casas de retiro pertenecientes a una religión, etc -, como aquellos que son usufructuados por una religión (sea esta como institución dueña o inquilina de la propiedad) y que, por tanto tienen una mayor carga sagrada, así no sean espacios específicos para el culto. Esta distinción no intenta perpetuar la dicotomización tajante entre sagrado y profano discutida previamente, sino identificar analíticamente lugares que se reconocen socialmente como seculares (lugares estatales y al aire libre) o religiosos (por eso hablamos de lugares religiosos y no de lugares sagrados). Sin embargo, y como veremos al aplicar la tipología, los usos de esos lugares se ven trastocados en la interacción de los actores con él, generando simultáneamente procesos de sacralización y secularización

Los organizadores de los eventos a clasificar en esta tipología son, bien las dependencias estatales o bien las religiones que interactúan con ellas. Si bien detallaremos la presencia de algunas religiones en la aplicación de la tipología, podemos ya indicar que estas se presentan al Estado en su faceta más institucional, contando entre las que tienen mayor participación a la Iglesia Católica; diferentes iglesias evangélicas (tanto de las llamadas históricas como pentecostales); iglesias "posevangélicas" (como la Iglesia de Jesucristo de los Santos de los Últimos Días); el judaísmo y el Islam a través de distintas asociaciones; religiones de matriz africana (estas también mediadas muchas veces por organizaciones que las nuclean); budistas y una serie de religiones con un número acotado de fieles en el país o en la región, pero con una búsqueda de ganar 
visibilidad en el espacio público (solo para mencionar las más presentes, la Iglesia Scientology, la fe Baha'i, los sikh, etc.)

En el caso de las dependencias estatales, tomaremos para esta primera clasificación aquellos eventos que cuentan con algún tipo de adhesión formal $\mathrm{u}$ organizacional por parte de las entidades estudiadas, dejando para próximas investigaciones otros eventos que pueden darse sin apoyo o participación de estas direcciones, pero que incluyen temas vinculados a lo religioso y cuentan con apoyo $\mathrm{u}$ organización estatal (por ejemplo, eventos organizados por el INADI-Instituto Nacional contra la Discriminación, la Xenofobia y el Racismo-, o actividades coordinadas por el área de desarrollo social de los distintos niveles de gobierno, etc.).

De esta forma quedan conformados seis tipos de interacciones: tres organizadas por las direcciones de culto(s), y tres organizadas por las diversas religiones. A continuación, presentamos la tabla de la tipología con una descripción genérica para luego contrastar esta matriz con las actividades de las direcciones estudiadas.

\begin{tabular}{|l|c|c|c|}
\hline \multirow{2}{*}{ Lugar } & \multicolumn{2}{|c|}{ Lugares seculares } & \multirow{2}{*}{ Lugares religiosos } \\
\cline { 2 - 3 } Organizador & Al aire libre & Estatales & $\mathrm{C}$ \\
\hline Dirección de Cultos & $\mathrm{A}$ & $\mathrm{B}$ & $\mathrm{F}$ \\
\hline Religiones & $\mathrm{D}$ & $\mathrm{E}$ & \\
\hline
\end{tabular}

Tabla 1. Tipología de la interacción en el espacio público.

Fuente: elaboración propia.

A. Eventos organizados por las direcciones en lugares públicos al aire libre: ferias y exposiciones, establecen una relación donde el Estado decide visibilizar determinadas religiones, legitimando su participación en el espacio público (aunque muchas veces esto no impacte necesariamente en la puesta en marcha de políticas públicas compartidas). La invitación suele provenir del Estado de forma más bien abierta a las comunidades religiosas en su conjunto (previendo la participación de algunos actores claves, como la Iglesia Católica o iglesias evangélicas de peso en la comunidad), y son las religiones las que deciden participar o buscan ganar visibilidad a partir de ser convocadas o tenidas en cuenta. La disposición en forma de feria al aire libre propicia la circulación, tanto entre diversos cultos que se acercan a los stands vecinos, como a los 
transeúntes ocasionales. Estos últimos pueden acercarse con intención de curiosear, o verlo de lejos como un espacio de potencial conversión, y por lo tanto sospechoso.

B. Eventos organizados por las direcciones en lugares estatales: charlas, conferencias, o jornadas, dan cuenta de una mirada un tanto más regulada sobre la participación religiosa en el espacio público, pues es el Estado el que fija una agenda más protocolar y pautada que la de los eventos previos, invita a los oradores y extiende la participación a determinados agentes religiosos, estatales y de la comunidad (incluso cuando algunos de estos eventos sean de acceso público). Suele producirse una invitación a través de medios de comunicación, pero no es común que se extienda mucho más allá de las comunidades religiosas interesadas.

C. Eventos organizados por el Estado en lugares religiosos: estos son menos frecuentes, pero pueden dar cuenta de una vía de comunicación más arraigada con las religiones, porque supone la apertura de estas a la intervención estatal en el lugar que tiene una significación especial -las más de las veces sagrado- para ellas. Aquí suele participar la comunidad de origen y gente interesada en el diálogo interreligioso, aunque, como veremos más adelante, también son momentos de apertura a la comunidad en general, con el Estado como garante del orden y la seguridad del evento.

D. Eventos organizados por las religiones en lugares al aire libre: principalmente peregrinaciones y festivales ${ }^{6}$, si bien no apelan a la relación con el Estado requieren de este para su logística. Consideramos importante este punto pues la logística de eventos religiosos es una de las funciones principales de las direcciones de cultos y visibiliza la presencia del Estado en eventos que podrían pensarse en una primera instancia como puramente religiosos. Cabe aquí realizar la aclaración de que la mayoría de estos eventos se realizaban mucho antes de la existencia de estas dependencias y suponían vínculos entre el Estado y las religiones de larga data. En este sentido, la presencia de estas oficinas viene a cumplir una función organizadora y centralizadora de algo que ya sucedía, y que debe muchas veces negociar - sobre todo con la Iglesia Católica - para ser reconocida como la cara del Estado frente a estos eventos.

\footnotetext{
${ }^{6}$ Existe una frondosa bibliografía nacional e internacional sobre fiestas y peregrinaciones, y su relación con el espacio público. Sólo para indicar una referencia, los textos de Funes (2019) y Flores (2018) realizan una revisión de trabajos que tratan estas temáticas. De la misma manera, Flores tiene una profusa producción sobre la materia, como puede verse en Flores (2015).

Este tipo particular de eventos es reconocido históricamente en el país como un espacio no sólo de devoción religiosa, sino también de disputa política, con más efectividad quizás que otras expresiones (CARBONELLI Y GIMÉNEZ BÉLIVEAU, 2018). 
E. Eventos organizados por las religiones en lugares estatales: nuevamente, la intervención de un agente en el lugar que le es ajeno, suponen un vínculo sostenido, en este caso permitiendo a las religiones concebir el uso del lugar estatal como habitable y disponible para eventos propios. Aquí podemos encontrar tanto el préstamo de lugares estatales a una determinada religión, como encuentros interreligiosos cuya organización parte de las religiones. Los lugares estatales privilegiados en estos casos son teatros, auditorios, salones de exposiciones.

F. Eventos organizados por las religiones con participación estatal: celebraciones religiosas, conmemoraciones, Tedeums. Este tipo de eventos son los más tradicionales en las relaciones entre religiones y Estado, pues suponen el sostenimiento de un cierto nivel de respeto de las religiones hacia la investidura estatal, y del Estado a la presencia religiosa legitimada en su territorio. El caso de los eventos con la Iglesia Católica es el más presente, conforme a la historia local, pero progresivamente se ha hecho más significativa la presencia de eventos de otras religiones. También han aumentado las invitaciones protocolares a eventos interreligiosos convocados por organizaciones no gubernamentales.

A continuación, aplicaremos esta tipología a las situaciones relevadas en las direcciones, introduciendo someramente a las mismas. Como podemos notar, el Estado toma el rol de organizador mayormente en lugares seculares, sus propias oficinas y edificios, y lugares al aire libre (los cuales, al menos administrativamente, configuran parte del territorio propiamente estatal), teniendo menor presencia cuando esto supone la intromisión en lugares significativos para las religiones. A su vez, la presencia religiosa gana diversos lugares seculares al aire libre -de forma que incluso muchas veces se invisibiliza el accionar estatal allí- y hace partícipe al Estado en sus lugares religiosos, pero debe negociar el ingreso a lugares estatales, sobre todo cuando se trata de religiones con poca presencia en el territorio que administran estas direcciones.

Estas seis instancias ponen en relieve una puja por la visibilización en el espacio público, tanto de las religiones como de las propias oficinas estatales, que no solo legitiman o deslegitiman la participación de ciertas creencias en el espacio público, sino que también en estas actividades buscan ganar presencia en los entramados estatales en que se encuentran insertas. Los lugares seculares más “neutrales" -la calle, la plaza, la ruta, la feria- abren más el juego a que los actores puedan negociar entre ellos y con la comunidad en general la pertinencia de su accionar en el espacio público; mientras que 
las presencias cruzadas en lugares que les son propios implican otro nivel de negociación, pues se configura un espacio público dominado por quien organiza el evento.

\section{Configurando el espacio público: la tipología puesta en juego}

En este contexto general se enmarca la acción de las tres direcciones a abordar, las cuales, como hemos mencionado, responden a distintos niveles de gobierno. Las tres tienen en común la cercanía geográfica, y que se trata de oficinas insertas en localidades importantes para la política de la región. Describiremos ahora brevemente a cada una de estas entidades, ubicándolas en el entramado estatal para luego analizar su accionar en el espacio público a partir de nuestra tipología.

\section{La Dirección General de Cultos (Ciudad autónoma de Buenos Aires)}

La Dirección General de Cultos (DGC) es parte del municipio de la Ciudad de Buenos Aires, la capital del país, una ciudad cosmopolita con una fuerte tradición migratoria y de convivencia de diversos credos (CELA HEFFEL, 2015). Esto permite comprender que la oficina busque, como marca característica, incorporar la diversidad religiosa como parte del acervo cultural de la ciudad. Proviene de un área de Colectividades y Cultos, que fundada en 2002, dependía de la Dirección General de Derechos Humanos. En diciembre de 2003 se crea la Dirección General Adjunta de Cultos (decreto 2696/2003), pasando a ser Dirección General en 2006. Su objetivo principal es establecer una interlocución ordenada y orgánica entre las distintas religiones y el Gobierno de la Ciudad (CELA HEFFEL, 2015). Es una oficina que cuenta con personal idóneo para las tareas que realiza, muchos de ellos con formación en teología o experiencia de investigación en temas de religión.

Se promueve a sí misma como un espacio de diálogo interreligioso para la ciudad, y sus funcionarios suelen hacer clara referencia en sus instancias públicas a la importancia cultural de la presencia religiosa en el territorio. Para ello la Dirección despliega un importante abanico de actividades a lo que se suma la participación en eventos organizados por las diversas religiones y la publicación de documentos informativos, como la "Guía de lugares de culto de la Ciudad de Buenos Aires", o un 
calendario anual con las festividades religiosas y fotografías de los cultos con los que mantiene relación.

Nos interesa destacar que entre sus objetivos se encuentra acompañar a las instituciones religiosas en las actividades de acción social que llevan adelante, ser nexo entre las diferentes áreas de gobierno y las comunidades de fe, y, particularmente, gestionar los lugares públicos que las religiones soliciten para expresarse. Esto quiere decir que una de sus competencias específicas es habilitar lugares públicos, ya sean plazas, calles y avenidas, hasta teatros, centros culturales u otros espacios para la expresión de las comunidades religiosas. La DGC recibe el pedido y lo efectiviza en coordinación con otras oficinas del municipio, facilitando muchas veces la logística necesaria para que suceda. A esto la Dirección suma la promoción del turismo religioso y la puesta en marcha progresiva de espacios de gestión de políticas públicas consensuadas con las diversas religiones. También impulsa un grupo de jóvenes, la Red Interreligiosa de Jóvenes de la Ciudad de Buenos Aires (RIJBA), que se reúnen a dialogar y participan de varias de las actividades de la Dirección.

\begin{tabular}{|c|c|c|c|}
\hline \multirow{2}{*}{ Organizador } & \multicolumn{2}{|c|}{ Lugares seculares } & \multirow{2}{*}{ Lugares religiosos } \\
\hline & $\mathrm{Al}$ aire libre & Estatales & \\
\hline Dirección de Cultos & $\begin{array}{c}\text { Feria por la Paz } \\
\text { Feria de } \\
\text { Pascua/Pesaj } \\
\text { Feria del Año Nuevo } \\
\text { Judío (y otras } \\
\text { festividades) } \\
\text { Festival BA del } \\
\text { Encuentro }\end{array}$ & $\begin{array}{c}\text { Foro Buenos Aires } \\
\text { Ciudad del } \\
\text { Encuentro y el } \\
\text { Diálogo } \\
\text { Interreligioso (2 } \\
\text { ediciones) }\end{array}$ & $\begin{array}{c}\text { Visitas guiadas } \\
\text { semanales a templos } \\
\text { de la ciudad } \\
\text { Noche de los } \\
\text { Templos (anual, } \\
\text { cuatro ediciones) } \\
\text { Visitas del } \\
\text { intendente }\end{array}$ \\
\hline Religiones & $\begin{array}{c}\text { Peregrinaciones } \\
\text { Vía Crucis por la } \\
\text { ciudad } \\
\text { Campañas } \\
\text { evangélicas }\end{array}$ & $\begin{array}{c}\text { Evento grupo Alba } \\
\text { (Islam) } \\
\text { Foro de Libertad } \\
\text { Religiosa } \\
\text { (CALIR/IRLA) }\end{array}$ & $\begin{array}{c}\text { Tedeum, misas } \\
\text { católicas, } \\
\text { celebraciones judías, } \\
\text { islámicas, } \\
\text { evangélicas. } \\
\text { Fiesta de Iemanjá en } \\
\text { Mar del Plata }^{7}\end{array}$ \\
\hline
\end{tabular}

Tabla 2. Tipología aplicada a la Dirección General de Culto (CABA).

Fuente: elaboración propia.

\footnotetext{
${ }^{7}$ Aquí hay un desplazamiento espacial, de ciudad de Buenos Aires a la ciudad costera de Mar del Plata, en la provincia de Buenos Aires (son unos 400 kilómetros por autopista), dado que el organizador de la fiesta tiene su templo en Buenos Aires y viaja anualmente a realizar las ofrendas a esta playa, que es una de las más icónicas de la Argentina. 
Si observamos ahora el despliegue de sus acciones a través de nuestra tipología, podemos dar cuenta de la cantidad de actividades que la Dirección despliega, que incluyen tanto al catolicismo como a las religiones históricas (judaísmo e islam) sin, dejar de lado a las minorías religiosas. Un punto a destacar es el evento "Festival BA del Encuentro" que fue primero marcadamente religioso, pero luego viró a un tinte más cultural, fijándose en una plaza pública, en la que se establece un escenario como "Espacio interreligioso de la Ciudad" 8 . De esta manera el Estado convierte un lugar secular al aire libre en un lugar potencialmente religioso (si bien, hasta donde pudimos saber, no se ha prestado aún para eventos coordinados por una religión en particular), aunque en los eventos que tienen lugar allí invita a cantantes famosos (en la última edición estuvo presente Soledad Pastoruti), diluyendo lo religioso en el espacio público como parte de la construcción discursiva de Buenos Aires como una ciudad cosmopolita.

En dependencias públicas (en este caso la Legislatura porteña y la sede del gobierno de la ciudad en Parque Patricios) se desarrollaron las dos ediciones del Foro orientado a la remarcar el diálogo interreligioso, a partir de ubicar la diversidad de la mano de la inmigración. Por otro lado, cabe destacar la puesta a disposición de la sede del gobierno de la ciudad para la realización del Foro de Libertad Religiosa en al año 2016, en el que se reunieron grupos religiosos nucleados en el CALIR. Este duró varios días y contó con la presencia del Director General, que incluso moderó un panel sobre símbolos religiosos y espacio público (GARCÍA BOSSIO, 2017).

Finalmente, nos gustaría destacar de esta Dirección su presencia sostenida en lugares religiosos, a través de dos actividades que ya son parte característica de la actual gestión de la dependencia: las visitas guiadas semanales a templos de la ciudad y la Noche de los Templos, evento anual en que distintos lugares de culto abren para ser recorridos por los vecinos. Aquí la DGC aporta la logística de seguridad para el evento y coordina visitas guiadas por los lugares religiosos de distintos barrios. Dentro de cada templo son las religiones las que cuentan de qué se tratan sus prácticas y, en algunos casos, ofrecen espectáculos y comidas típicas. En ambos casos, durante los primeros años, los recorridos incluían los lugares sagrados de las religiones más tradicionales (catolicismo,

\footnotetext{
${ }^{8}$ El Espacio es una estructura semejante a un anfiteatro (pero sin gradas), con un emplazamiento para un escenario. Alrededor se sitúan los stands de las distintas religiones y otros de comidas. Según la propia página de la ciudad, el Espacio Interreligioso fue seleccionado como uno de los proyectos modelos a presentar en 10 $0^{\underline{a}}$ Asamblea Mundial de Religiones por la Paz (https://www.buenosaires.gob.ar/cultos/noticias/el-espacio-interreligioso-de-la-ciudaddestacado-nivel-mundial). 
protestantismo histórico, judaísmo e islam) pero, progresivamente, se han ido abriendo, incluyendo actualmente a la comunidad Sikh Darma Argentina, comunidades budistas, e incluso afrorreligiosas, entre otras. Las religiones, en general, se encuentran abiertas a este tipo de actividades porque les dan visibilidad y, para aquellas más estigmatizadas, implica un importante reconocimiento estatal. A su vez, la variedad de religiones (y, sobre todo, de estéticas diversas) refuerza la construcción del carácter cosmopolita de la ciudad en su espacio público.

\section{La Dirección Provincial de Cultos (Provincia de Buenos Aires)}

La Provincia de Buenos Aires tiene la trayectoria de organización estatal de lo religioso más antigua entre los casos estudiados, una historia signada por el esfuerzo de sus directores para mantener cierta presencia en un territorio extenso y muy heterogéneo (GARCÍA BOSSIO, 2018) con una fuerte presencia del catolicismo.

En el año 2001 se creó la Subsecretaría de Cultos, que extiende a otros cultos las funciones ya existentes de la "Unidad de Coordinación y Enlace con la Jerarquía Eclesiástica de la Iglesia Católica”. En el año 2002 pasó a denominarse Dirección Provincial de Culto. Si bien mantenía un espacio privilegiado de relación con la Jerarquía Eclesiástica de la Iglesia Católica para el desarrollo de políticas públicas en materia social, incorporaba las relaciones del Gobierno provincial con todas las iglesias, confesiones y comunidades religiosas de su territorio, proponiendo como fin el garantizar la libertad religiosa.

En el año 2008 pasó a estar en primer lugar entre sus misiones y funciones el diálogo con "todas las iglesias, confesiones y comunidades religiosas". En 2015, la Dirección, ahora de Cultos (en plural), modificó nuevamente sus misiones y funciones: ya no mencionan a la Iglesia Católica de forma explícita, sino que su función central es la de "coordinar y generar vínculos con los cultos reconocidos en el ámbito de la Provincia de Buenos Aires" (decreto 46/15), promoviendo la investigación de las diferentes tradiciones religiosas y la cooperación con las instituciones religiosas en la "promoción de la participación ciudadana”. Podemos observar una progresiva traslación a una mayor "apertura" hacia las religiones no católicas. Es interesante destacar que hasta esta última configuración la vinculación primordial con la Iglesia Católica estaba fuertemente asociada al trabajo social y de ayuda humanitaria, pero indicando que el interlocutor frente al Estado era la jerarquía eclesiástica. 
Hacia 2018 fue “degradada” jerárquicamente y pasó a ser Área de Cultos, con su director como coordinador. Esto implicó una menor libertad para accionar para una dependencia de por sí con poco margen de acción por su lugar en el entramado estatal: una provincia con un complejo derrotero histórico y político que la une profundamente con lo que sucede a nivel nacional (OLLIER, 2010). Durante todo el período estudiado la Dirección nunca contó con más de seis o siete agentes estatales, lo que resulta muy reducido si pensamos que debería estar presente en toda la provincia, la cual concentraba en 2010 el 38\% de la población del país, y el 41,9\% de las religiones no católicas inscriptas en el Registro Nacional de Cultos (según datos de 2015, GARCÍA BOSSIO, 2018).

Esto es aún más complejo si pensamos que, en palabras del director, se proponía una función no "mediática" sino "ejecutiva”, entendiendo esto como "mantener y profundizar la relación que tiene con la Iglesia Católica y restablecer las relaciones (...) con el resto de las iglesias, con todas, especialmente con la diversidad y sus diferentes denominaciones de las iglesias evangélicas" (Entrevista al Director de Cultos, 2016). Esto nos permite explicar que el accionar de la Dirección esté concentrado mayormente en la ciudad de La Plata y el Conurbano bonaerense, dada la cercanía entre estos territorios y la creciente creación de oficinas municipales con tareas semejantes, lo que facilita la coordinación de proyectos conjuntos.

Otro de los puntos marcados como centrales por el director es el relacionado con resguardar a los ciudadanos en su libertad de expresar su religión, a partir del acompañamiento, coordinación y cuidado en eventos masivos, como son las peregrinaciones católicas o los encuentros evangélicos en lugares al aire libre. Allí la Dirección se ve a sí misma como garante de la libertad religiosa en la habilitación de los medios materiales, vía la articulación entre diversos sectores del gobierno provincial -e incluso con los gobiernos municipales-, considerando que es responsabilidad del Estado el buen desarrollo de las actividades que emprenden sus ciudadanos.

Un elemento que gana centralidad en esta gestión como unificador de las religiones, pero a su vez como una instancia de acción que trascienda al Estado como mero habilitador del diálogo entre los distintos credos, es la temática del consumo problemático de drogas. Ya desde hace tiempo el Estado ha descargado en las religiones parte de las políticas de prevención, atención y recuperación de la drogadependencia, incluyendo, además de a la ya histórica Iglesia Católica, a los evangélicos a la gestión pública, a modo de "rueda de auxilio" de lo político frente a las problemáticas sociales (CARBONELLI, 2015). Para ello la Dirección propuso realizar las “Expo Promo Salud”, 
ferias al aire libre donde diversas religiones pueden dar a conocer su trabajo en prevención y recuperación de usos problemáticos de drogas, desde una perspectiva donde dialogan salud, bienestar y cuidado, pero que al mismo tiempo no implica necesariamente una apertura a la generación de políticas públicas conjuntas con las religiones. (GARCÍA BOSSIO Y MONJEAU CASTRO, 2018). Entre 2016 y 2019 se realizaron once ediciones, ocho en el Conurbano Bonaerense (Quilmes, Florencio Varela, Moreno, Lomas de Zamora), dos en la ciudad de La Plata, (que contaron con el apoyo de la Dirección de Entidades y Culto del municipio) y una en Brandsen (localidad cercana a La Plata). Estos eventos contaron con representantes de católicos y evangélicos, pero también con otras religiones, como adventistas, la Iglesia Scientology y afroumbandistas. Progresivamente se fueron desplazando hacia lugares al aire libre, más periféricos dentro de las localidades, donde el consumo de drogas problemáticas es mayor, a la vez que se incorporaron meriendas y comidas para quienes participaran. En esta misma línea, pero en lugares religiosos, se encuentra la visita a comunidades terapéuticas, principalmente evangélicas (aunque en este caso no fueran eventos abiertos al público).

\begin{tabular}{|c|c|c|c|}
\hline \multirow{2}{*}{ Organizador } & \multicolumn{2}{|c|}{ Lugares seculares } & \multirow{2}{*}{ Lugares religiosos } \\
\hline & $\mathrm{Al}$ aire libre & Estatales & \\
\hline $\begin{array}{l}\text { Dirección Provincial } \\
\text { de Cultos }\end{array}$ & $\begin{array}{l}\text { Expo Promo Salud } \\
\text { (periódicas, } 11 \\
\text { ediciones) }\end{array}$ & $\begin{array}{c}\text { Día de la Libertad } \\
\text { Religiosa (3 ed.) } \\
\text { Día de las Iglesias } \\
\text { Evangélicas y del } \\
\text { Pastor Evangélico } \\
\text { Día de la Mujer en } \\
\text { Lanús } 2019 \\
\text { REDIJBA }\end{array}$ & $\begin{array}{l}\text { Visitas en el marco } \\
\text { de REDIJBA } \\
\text { Charla sobre } \\
\text { exención impositiva } \\
\text { de luz y gas (con } \\
\text { otros organismos } \\
\text { estatales) }\end{array}$ \\
\hline Religiones & $\begin{array}{c}\text { Peregrinaciones a } \\
\text { Luján y San Nicolás } \\
\text { Campañas } \\
\text { evangélicas }\end{array}$ & $\begin{array}{c}\text { Feria del Libro } \\
\text { Católico (Pasaje } \\
\text { Dardo Rocha, La } \\
\text { Plata) } \\
\text { Muestra sobre el } \\
\text { Holocausto con } \\
\text { AMIA (Centro } \\
\text { Cultural Islas } \\
\text { Malvinas, L.P.) }\end{array}$ & $\begin{array}{c}\text { Tedeum, misas } \\
\text { católicas, } \\
\text { celebraciones judías, } \\
\text { islámicas, } \\
\text { evangélicas }\end{array}$ \\
\hline
\end{tabular}

Tabla 3. Tipología aplicada a la Dirección Provincial de Cultos.

Fuente: elaboración propia. 
En lugares propiamente estatales, la Dirección desarrolló dos tipos de actividades: encuentros interreligiosos, como el día de la Libertad Religiosa y la celebración del Día de la Mujer en Lanús (en conjunto con la dirección municipal, se reconoció la labor social de mujeres de distintas religiones); y la puesta a disposición de salas de exhibición estatales para muestras católicas y judías. En el caso de los eventos por los 500 años de la reforma protestante (Día de las Iglesias Evangélicas) y del Pastor Evangélico (el tercer domingo de octubre), ninguna fue impulsada desde la Dirección, pero esta estuvo presente en la organización e invitaciones protocolares.

La articulación de la Dirección con lugares religiosos también responde a esta lógica más pragmática que orientada a la visibilidad de la diversidad, al impulsar una serie de charlas sobre exenciones impositivas que el gobierno nacional habilitó a los lugares de culto en los servicios de gas y electricidad durante el año 2019. Aquí las reuniones se llevaron a cabo en colaboración con los entes reguladores de ambos servicios y con colaboración de las direcciones de culto locales en espacios periféricos de cada localidad. La invitación a las religiones corrió por cuenta de los gobiernos locales.

Finalmente, en este caso quisiera destacar el intento de conformar una Red Interreligiosa Juvenil de la Provincia de Buenos Aires (REDIJBA), a semejanza de RIJBA en ciudad de Buenos Aires, que se proyectaba para realizar encuentros mensuales. Si bien no llegó a tener el alcance esperado, sí se realizaron encuentros con jóvenes de distintas confesiones (principalmente católicos, judíos y evangélicos) en lugares de culto, coordinando sus últimas acciones con la Dirección de La Plata.

La Dirección Provincial buscó conformar una vinculación con las religiones en el espacio público a partir de incentivar ejes temáticos en áreas específicas, con la intención de poder proyectar acciones conjuntas. Sin embargo, la extensión y heterogeneidad de la provincia (en términos religiosos, pero también políticos), dificultó el trabajo, tendiendo redes que pudieron extenderse sólo en un radio cercano y con el apoyo de los gobiernos locales.

\section{La Dirección de Entidades y Culto (ciudad de La Plata)}

La Dirección de Entidades y Culto de La Plata es la dependencia más recientemente creada de las que presentamos, parte de una pequeña oleada de creación de oficinas municipales relacionadas a las religiones (GARCÍA BOSSIO, 2018). Sin embargo, desplegó rápidamente una serie de actividades, a la vez que tiene la 
particularidad de haber tenido dos directoras, de perfiles muy distintos, en el transcurso de sus cuatro años de existencia.

Creada en el año 2015, dependía de la Secretaría General del poder ejecutivo de la ciudad de La Plata, capital de la provincia de Buenos Aires ${ }^{9}$. Tenía entre sus funciones el trabajo con entidades de bien público, en general, y con entidades religiosas, en particular. Esto llevaba a que las tareas se encontraran divididas entre los agentes, especializándose unos en el trabajo con las entidades de la sociedad civil y otros en las entidades religiosas. Al inicio la Dirección impulsó el contacto con las religiones presentes en la ciudad, a la vez que comenzó una política de difusión tanto a través de los medios de comunicación locales como desde la cuenta de Facebook de la Directora.

Ambas gestiones de la Dirección realizaron las tareas de informar protocolarmente a la intendencia de las festividades religiosas más importantes, participar en eventos religiosos, asesorar a las diversas religiones para la inscripción en el Registro Nacional de Cultos (la segunda gestión firmó un convenio con este y promovió capacitaciones) y poner en funcionamiento los permisos y la logística para actividades religiosas en lugares al aire libre.

\begin{tabular}{|c|c|c|c|}
\hline \multirow{2}{*}{ Organizador } & \multicolumn{2}{|c|}{ Lugares seculares } & \multirow{2}{*}{ Lugares religiosos } \\
\hline & $\mathrm{Al}$ aire libre & Estatales & \\
\hline $\begin{array}{l}\text { Dirección de } \\
\text { Entidades y Culto }\end{array}$ & $\begin{array}{c}\text { Expo Promo Salud } \\
\quad(2016 \text { y 2019) }\end{array}$ & $\begin{array}{c}\text { Charlas sobre salud } \\
\text { Premio mujeres } \\
\text { destacadas } \\
\text { Capacitaciones del } \\
\text { RNC } \\
\text { REDIJBA } \\
\text { Día de la Libertad } \\
\text { Religiosa (con } \\
\text { provincia) }\end{array}$ & $\begin{array}{c}\text { Visitas en el marco de } \\
\text { REDIJBA } \\
\text { Visitas a lugares de } \\
\text { culto con el Intendente } \\
\text { (en contexto electoral) }\end{array}$ \\
\hline Religiones & $\begin{array}{l}\text { Procesiones } \\
\text { católicas } \\
\text { Campañas } \\
\text { evangélicas }\end{array}$ & $\begin{array}{c}\text { Charla organizada } \\
\text { por la fe Baha’i } \\
\text { (Centro Cultural } \\
\text { Islas Malvinas) }\end{array}$ & $\begin{array}{c}\text { Tedeum, misas } \\
\text { católicas, celebraciones } \\
\text { judías, evangélicas y } \\
\text { ortodoxas } \\
\text { Día de la Libertad } \\
\text { Religiosa (Mesa de } \\
\text { Diálogo) }\end{array}$ \\
\hline
\end{tabular}

Tabla 4. Tipología aplicada a la Dirección de Entidades y Culto. Fuente: elaboración propia.

\footnotetext{
${ }^{9}$ Decimos dependía porque en la actualidad las funciones de diálogo con las religiones y con las entidades de bien público se separaron, y la Dirección de Cultos pasó a depender de Desarrollo Social. ESPACO E CULTURA, UERJ, RJ, JUN./JUL DE 2020, N. 47, P. 55-80. http://www.e-publicacoes.uerj.br/index.php/espacoecultura/
} 
En lugares al aire libre la Dirección puso parte de la logística y articuló con las religiones de la región para las dos ediciones de la Expo Promo Salud organizadas en La Plata junto con la Dirección Provincial de Cultos. Ambas directoras participaron de con la provincia del Día de la Libertad Religiosa, y la segunda gestión coordinó también encuentros de REDIJBA.

En lugares estatales, la primera gestión realizó paneles de diálogo interreligioso a partir de una temática como punto de partida (2016 y 2017). Allí se eligieron, en línea con las propuestas de otras direcciones, provinciales y municipales, temáticas asociadas a la salud. Los oradores fueron católicos, judíos y en una de las charlas participó también una joven budista invitada por el rabino. En ambas gestiones se realizaron para el Día de la Mujer eventos de reconocimiento a mujeres destacadas en su accionar con respecto al bien común en la ciudad (tanto por su labor artística, como profesional, o de servicio a la comunidad y acción social) unificando las funciones de entidades y culto. En la segunda gestión se habilitó un centro de exhibiciones municipal para que la fe Baha’i pudiera dar una conferencia con un especialista español, participando un agente de la Dirección de la misma.

En lugares religiosos, y en contexto de campaña electoral en el año 2019, la segunda directora coordinó una serie de visitas del intendente (que iba por la reelección) a lugares de culto, ya sea para tener una charla con la comunidad (como en el caso de algunas iglesias pentecostales) o como invitado a la conmemoración de los 100 años del templo metodista en la ciudad. En estos mismos lugares, pero en eventos organizados por las religiones, ambas gestiones participaron de las habituales invitaciones protocolares a festividades religiosas.

Finalmente, sobre esta Dirección me interesaría destacar la presencia de la segunda directora en la celebración por el Día de la Libertad Religiosa realizada por la Mesa de Diálogo Interreligioso de La Plata ${ }^{10}$, en la Iglesia de Jesucristo de los Santos de los Últimos Días, no solamente porque cumple con la participación del Estado en un evento religioso, sino también porque esta Mesa está coordinada por la exdirectora del

\footnotetext{
10 La Mesa de Diálogo Interreligioso de La Plata y Región Capital Bonaerense es un espacio interreligioso conformado por iniciativa de la ex directora de entidades y culto. Reúne miembros de la Iglesia Católica, Comunidad judía AMIA La Plata, Iglesia Evangélica Metodista Argentina, Iglesia Evangélica Luterana Unida, Iglesia de Jesucristo de los Santos de los Últimos Días, Asociación Social y Cultural Afro Umbandista (ASRAU), Fe Baha'i, Comunidad Musulmana Ahmadia, Ejército de Salvación y Escuela Científica Basilio. No es una mesa interreligiosa de carácter estatal, pero mantiene vínculos de diálogo con el Estado y de invitación protocolar a eventos por ella organizados. ESPAÇO E CULTURA, UERJ, RJ, JUN./JUL DE 2020, N. 47, P. 55-80. http://www.e-publicacoes.uerj.br/index.php/espacoecultura/
} 
municipio, que la formó a partir de su experiencia de gestión. De alguna manera, en este caso el Estado está presente en la configuración del espacio público no sólo en la presencia de su agente estatal, sino también en la medida en que la visibilización de la diversidad religiosa en la localidad (ciudad masona, pero con mucha presencia católica en el espacio público) está atravesada también por la experiencia de los actores en su vinculación con el Estado, que fue lo que permitió el inicio de ese espacio interreligioso.

\section{Conclusiones}

En este trabajo nos propusimos indagar en las consecuencias de las interacciones entre las diversas religiones y el Estado en el espacio público. Intentamos ver allí una forma de regulación que no sólo se produce desde el Estado hacia las religiones, sino que también nos permite pensar cómo las religiones intervienen en lo estatal a partir de su aparición en el espacio público, siguiendo la presencia de ambos actores en lugares socialmente significativos. Para ello construimos una tipología que nos permita observar tanto las prácticas de sacralización de lugares seculares, como las prácticas de legitimación cruzada, entre las religiones y las direcciones, ambas buscando ser reconocidas en el espacio público.

Siguiendo las características generales de tres dependencias estatales de nivel subnacional, buscamos comprender cómo las burocracias locales establecen vínculos con las religiones en su territorio; a la vez que las religiones intentan reconocerse en el espacio público como forma de obtención de legitimidad. Así pudimos describir una serie de situaciones de intervención, donde si bien aún la Iglesia Católica es un actor preponderante, podemos ver la participación de otras religiones, tanto cristianas, como del judaísmo y el Islam. También han comenzado a visibilizarse religiones menos conocidas en el ámbito local, como es el caso de la Iglesia Scientology, o algunas religiones orientales, fundamentalmente en Ciudad de Buenos Aires, pero también en La Plata con la presencia de la fe Baha'i.

Si comprendemos que existe una dimensión espacial de la constitución de las religiones en una sociedad (FRIGERIO, 2017) este tipo de análisis nos permite ver cómo las religiones vuelven lugares significativos para sí determinados lugares seculares, a la vez que se legitiman frente al resto de la sociedad al poder significar su participación en esos lugares como válida. Sería interesante pensar hasta qué punto estas participaciones pueden llevar progresivamente, o no, a una situación que vaya de la diversidad religiosa 
-actualmente existente en Argentina- a una situación de mayor pluralismo religioso. La visibilización de las religiones en el espacio público, como la participación de agentes estatales en eventos en lugares religiosos, puede tender a una mayor aceptación social de los grupos religiosos, lo que podría conllevar en el mediano o largo plazo al reconocimiento de un pluralismo radical (al decir de SEGATO, 2007) que no achate las diferencias, sino que las reconozca como vigentes en el espacio y en nuestra vida. Cómo esto puede afectar a la laicidad del Estado es tema para próximas investigaciones.

\section{AGRADECIMIENTOS}

Este trabajo es parte de la investigación doctoral que es posible gracias al apoyo del Consejo Nacional de Investigaciones Científicas y Técnicas. Una versión previa fue presentada en la XII Reunión de Antropología del Mercosur, en una mesa coordinada por Nicolás Viotti, Emerson Giumbelli y Juan Scuro. Agradezco a ellos y a quienes participaron del encuentro por sus comentarios y sugerencias.

La versión actual se vio nutrida por la lúcida lectura de la Confra, grupo sororo de socioantropólogas, colegas y amigas. Que hacer ciencia sea siempre igual de placentero que recibir sus comentarios.

\section{REFERENCIAS BIBLIOGRÁFICAS}

ALGRANTI, Joaquín; CALCAGNO, Nicolás; GIMÉNEZ BÉLIVEAU, Verónica; RUBIO, Berenice. Marcas religiosas en el Área Metropolitana de Buenos Aires. In: MALLIMACI, Fortunato (Dir.), Atlas de las creencias religiosas en la Argentina. Buenos Aires: Biblos, 2013.

CARBONELLI, Marcos. Pan y palabras. La inserción evangélica en la gestión pública en Argentina. Religião e Sociedade. Buenos Aires, v. 2, n. 35, 2015, p. 73-95.

CATOGgIO, María Soledad. Gestión y regulación de la diversidad religiosa. Políticas de "reconocimiento" estatal: el Registro Nacional de Cultos. In: MALLIMACI, Fortunato (Org.), Religión y política. Perspectivas desde América Latina y Europa. Buenos Aires: Biblos, 2008.

CELA HEFFEL, David. Interacción de las iglesias protestantes históricas con la Dirección General de Cultos de la Ciudad Autónoma de Buenos Aires (2003-2007). Un estudio de caso. Horizontes Decoloniales. Buenos Aires, v. 1, n. 1, 2015, p. 196-233.

DI STEFANO, Roberto. Le processus historique de sécularisation et de laïcité en Amérique latine. In: MARTIN, Arnaud (Dir.), La laïcité en Amérique latine. Paris : L’Harmattan, 2014. 
ESQUIVEL, Juan Cruz. Religión y política en Argentina. La influencia religiosa en las Constituciones provinciales. XXVII Congreso de la Asociación Latinoamericana de Sociología. Buenos Aires: Asociación Latinoamericana de Sociología, 2009.

FLORES, Fabián Claudio. Espacialidades peregrinas: el caso de la peregrinación juvenil a pie a Luján. Espaço e Cultura. Río de Janeiro, n. 37, 2015, p. 116-136.

Lo religioso y el espacio. Apuntes desde la Geografía. In: CLOCET DA SILVA, Ana Rosa; DI STEFANO, Roberto. História das religiões em perspectiva: desafios conceituais, diálogos interdisciplinares e questões metodológicas. Curitiba: Prismas, 2018.

FRIGERIO, Alejandro. Questioning religious monopolies and free markets: The role of the State, the church(es) and secular agents in the management of religion in Argentina. Citizenship Studies, n. 16, 2012, p. $997-1011$.

Religion Out of Place: Social Regulation of Evangelical Expansion in Buenos Aires. In MAPRIL, José; BLANES, Ruy; GIUMBELli, Emerson; WILSON, Erin K. (Eds.), Secularisms in a Postsecular Age? Cham: Palgrave Macmillan, 2017.

FRIGERIO, Alejandro y WYNARCZYK, Hilario. Diversidad no es lo mismo que pluralismo: cambios en el campo religioso argentino (1985-2000) y lucha de los evangélicos por sus derechos religiosos. Sociedade e Estado. Brasilia, v. 2, n. 23, 2008, p. 227-260.

FUNES, María Eugenia. El espacio en los estudios sociales de la religión: perspectivas, objetos y problemas emergentes en las agendas de investigación latinoamericanas. REVER. Sao Paulo, v. 19 , n. 2 , 2019, p. $213-227$.

GARCÍA BOSSIO, María Pilar. ¿Todos, algunos, ninguno? Símbolos religiosos en el espacio público: debates desde las religiones. XII Jornadas de Sociología. Buenos Aires: UBA, 2017.

La laicidade problematizada. Su uso para pensar organismos estatales. Religião \& Sociedade. Rio de Janeiro, v. 38, n. 2, 2018, p. 148-173.

GARCÍA BOSSIO, María Pilar; MONJEAU CASTRO, Catalina (2018). Bienestar y salud: entre las religiones y el Estado. El caso de las Expo Promo Salud en la Provincia de Buenos Aires. Salud colectiva. Lanús, v. 14, n. 2, 2018, p. 323-340.

GIUMBELLI, Emerson. A presença do religioso no espaço público: modalidades no Brasil. Religião e Sociedade. Rio de Janeiro, v. 28, n. 2, 2008, p. 80-101.

Para estudar a laicidade, procure o religioso. In: GIMÉNEZ BÉLIVEAU, Verónica; GIUMBELLI, Emerson. (Coord.), Religión, cultura y política en las sociedades del siglo XXI. Buenos Aires: Biblos, 2013.

GUPTA, Akhil. Fronteras borrosas: el discurso de la corrupción, la cultura política y el estado imaginado. In: ABRAMS, Philip; GUPTA, Akhil; MITCHELL, Timothy. Antropología del Estado. México: Fondo de Cultura Económica, 2015.

MALliMACI, Fortunato. (Dir.), Atlas de las creencias religiosas en la Argentina. Buenos Aires: Biblos, 2013.

Intelectual, 2015.

El mito de la Argentina laica. Catolicismo, política y Estado. Buenos Aires: Capital 
MALLIMACI, Fortunato; GIMÉNEZ BÉLIVEAU, Verónica; ESQUIVEL, Juan Cruz; IRRAZÁBAL, Gabriela. Sociedad y Religión en Movimiento. Segunda Encuesta Nacional sobre Creencias y Actitudes Religiosas en la Argentina. Informe de Investigación, n. 25. Buenos Aires: CEIL-CONICET, 2019.

MARTÍN, Eloísa. Aportes al concepto de "religiosidad popular": una revisión de la bibliografía argentina. In: CAROZZI, María Julia; CERIANI CERNADAS, Cesar (Coord.), Ciencias sociales y religión en América Latina. Perspectivas en debate. Buenos Aires: Biblos, 2007.

OLLIER, María Matilde. Atrapada sin salida. Buenos Aires en la política nacional. Buenos Aires: Universidad Nacional de General San Martín, 2010.

SEGATO, Rita. La faccionalización de la república y el paisaje religioso como índice de una nueva territorialidad. In ALONSO, Aurelio. (Comp.), América Latina y el Caribe: Territorios religiosos y desafíos para el diálogo. Buenos Aires: CLACSO, 2008.

La nación y sus otros. Raza, etnicidad y diversidad religiosa en tiempos de Políticas de la Identidad. Buenos Aires: Prometeo, 2007. 